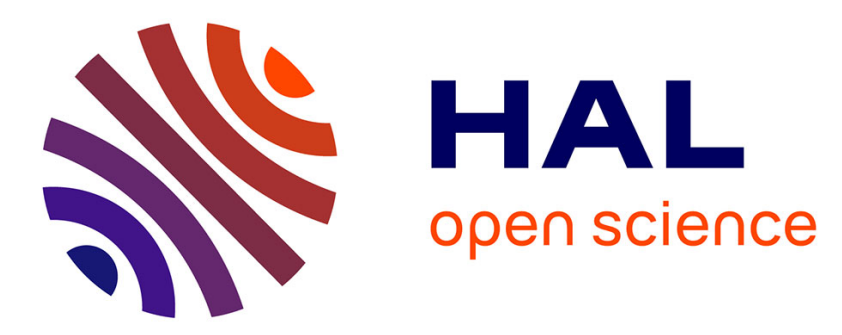

\title{
Unexpected temporal evolution of atomic spectral lines of aluminum in a laser induced breakdown spectroscopy experiment
}

\author{
Rawad Saad, Daniel L'Hermite, Bruno Bousquet
}

\section{- To cite this version:}

Rawad Saad, Daniel L'Hermite, Bruno Bousquet. Unexpected temporal evolution of atomic spectral lines of aluminum in a laser induced breakdown spectroscopy experiment. Spectrochimica Acta Part B: Atomic Spectroscopy, 2014, 101, pp.330-334. 10.1016/j.sab.2014.09.017 . hal-01094338

\section{HAL Id: hal-01094338 \\ https://hal.science/hal-01094338}

Submitted on 12 Dec 2014

HAL is a multi-disciplinary open access archive for the deposit and dissemination of scientific research documents, whether they are published or not. The documents may come from teaching and research institutions in France or abroad, or from public or private research centers.
L'archive ouverte pluridisciplinaire HAL, est destinée au dépôt et à la diffusion de documents scientifiques de niveau recherche, publiés ou non, émanant des établissements d'enseignement et de recherche français ou étrangers, des laboratoires publics ou privés.

\section{(ㄷ)(1) $\$$}

Distributed under a Creative Commons Attribution - NonCommerciall 4.0 International 


\title{
Unexpected temporal evolution of atomic spectral lines of aluminum in a
}

\author{
laser induced breakdown spectroscopy experiment
}

\author{
Rawad Saad ${ }^{\text {a }}$, Daniel L'Hermite ${ }^{\text {a,* }}$, Bruno Bousquet ${ }^{\text {b }}$ \\ a CEA, DEN, DPC, SEARS, LANIE, 91191 Gif-sur-Yvette, France \\ b LOMA, Université de Bordeaux, CNRS, 351 Cours de la Libération, 33405 Talence Cedex, France
}

Keywords:

UBS

Plasma temperature

Temporal evolution

Collisional energy transfer

Molecular recombination

\begin{abstract}
A B S T R A C T
The temporal evolution of the laser induced breakdown (LIBS) signal of a pure aluminum sample was studied under nitrogen and air atmospheres. In addition to the usual decrease of signal due to plasma cooling, unexpected temporal evolutions were observed for a spectral lines of aluminum, which revealed the existence of collisional energy transfer effects. Furthermore, molecular bands of AIN and AlO were observed in the LIBS spectra, indicat ing recombination of aluminum with the ambient gas. Within the experimental conditions reported in this study, both collisional energy transfer and recombination processes occurred around $1.5 \mu \mathrm{s}$ after the laser shot. This highlights the possible influence of collisional and chemical effects inside the plasma that can play a role on LIBS signals.
\end{abstract}

\section{Introduction}

One of the most widespread rapid multi elemental techniques for quantitative analysis is laser induced breakdown spectroscopy (LIBS) [1 4 ]. It is based on the atomic emission of laser induced plasma resulting from the laser ablation in the case of a solid sample. Moreover, liquid and gas samples can also be ionized by a laser beam and thus an alyzed by UBS. This technique has established itself as an analytical tool in different fields of applications such as the spatial application on Mars $[5,6]$, nuclear industry $[7,8]$, analysis of pigments $[9,10]$, aerosols $[11,12]$, polymers [13,14], metallurgy [15,16], environment [17], art and cultural heritage $[18,19]$, pharmacy and biology $[20,21]$. This list illustrates the fact that LIBS is a very versatile analytical technique presenting high spatial resolution and possible remote measurements [22].

Different mechanisms and phenomena could affect the LIBS signal such as instrumental fluctuations, shot noise, spectral interferences, self absorption, and matrix effects. Several research groups worked on different normalization methods to correct these phenomena. Zorov et al. have outlined most of them in a recent review paper [23]. On the other hand, physico chemical phenomena occurring in LIBS plasma still remain less studied. The chemical reaction $\mathrm{Al}+\mathrm{O}_{2} \rightarrow \mathrm{AlO}+\mathrm{O}$ was first studied by Dagdigian et al. [24] in a beam gas arrangement

\footnotetext{
* Corresponding author. Tel.: 33 (0)1 69089504.

E-mail addresses: rawad.saad@cea.fr (R. Saad), daniel.Ihermite@cea.fr (D. L'Hermite), bruno.bousquet@u-bordeaux1.fr (B. Bousquet).
}

in the framework of a laser fluorescence study. In their work, the state distribution, the dissociation energy and the radiative lifetime of AlO were derived. Another group studied the dynamics of the above reac tion and found that the relative reactivity for $\mathrm{Al}\left({ }^{2} P_{1 / 2}\right)$ and $\mathrm{Al}\left({ }^{2} P_{3 / 2}\right)$ depend on the collision energy amount [25] and thus on the plasma temperature. Moreover, Misra and Thareja showed that aluminum re acts with nitrogen to form the molecule AlN in the framework of alumi num films deposition in nitrogen ambient atmospheres [26]. In another study, Sharma and Thareja studied the formation of aluminum nitride [27] and concluded that the ionized states of Al II and N II contributed to the formation of AIN. In addition, Dors et al. worked on the determi nation of the AlO spectroscopic temperature by the use of the modified diatomic Boltzmann plot and the Nelder Mead algorithm in the fitting of the recorded spectrum [28]. After this, in a recent paper [29], Parigger showed that atomic and molecular emissions should be evaluated together and in the same time in order to overcome the occurrence of superposition spectra in the plasma decay. He suggested using spatially and temporally resolved LIBS experiments to understand the different phenomena. Within the framework of a $\mathrm{PhD}$ thesis in our research group [30], matrix effect was analyzed during LIBS experiment. A loss of the signal intensity was noticed but not totally explained by the self absorption phenomena. A hypothesis of the presence of chemical reactions in the plasma was proposed. Consequently, in order to study the chemical reactions in the plasma, we choose to treat the simple case of a pure aluminum sample. In this paper, we focused on the pecu liar temporal evolution of the observed $\mathrm{Al} \mathrm{I}$ lines during the plasma expansion. The results presented here were obtained under air and nitrogen atmospheres and at ambient pressure. We describe in a first 
step the experimental setup for the acquisition of time resolved LIBS spectra. Then, we present the results and discussions related to the temporal evolution of the chosen Al I lines.

\section{Experimental}

The whole experimental setup is the MobiLIBS @ equipment from IVEA Solutions, France. The plasma was generated at atmospheric pres sure using a Nd:YAG laser operating at $266 \mathrm{~nm}$ and providing $5 \mathrm{~ns}$ (FWHM) pulses at $20 \mathrm{~Hz}$ repetition rate. A $25 \mathrm{~cm}$ focal length lens was used to focus the laser beam onto the sample surface. The maximum laser pulse energy was $4 \mathrm{~mJ}$ and the spot diameter at the sample surface was equal to $50 \mu \mathrm{m}$ so the irradiance was approximately $40 \mathrm{GW} \mathrm{cm}$. The emission from the plasma was collected in the direction of the inci dent laser beam, and transmitted through optical fiber to the entrance slit of a high resolution spectrometer (Mechelle, Andor Technology, re solving power $\lambda / \Delta \lambda=4000$ ) equipped with an intensified CCD camera. The ICCD sensitivity was equal to 400 counts/photoelectron which corresponds to a gain of 200 set on the MCP software. In this work, a super pure aluminum sample (198f TechLab) with trace elements of $\mathrm{Si}(0.002 \%), \mathrm{Fe}(0.001 \%)$ and $\mathrm{Cu}(0.005 \%)$, was analyzed under two different ambient gases (nitrogen and air) at atmospheric pressure. Fig. 1 displays a part of the Grotrian diagram of aluminum limited to the spectral lines of interest for this work. The Einstein coefficients $(A)$ and the upper energy level values $\left(E_{\mathrm{k}}\right)$ of the selected $\mathrm{Al} I \mathrm{I}$ lines listed in Table 1 are provided by the Kurucz atomic spectral line database [31]. In order to study the temporal behavior of the spectral lines of interest, the delay time between the laser pulse and the signal acquisition was tuned within the range of $0.215 \mu \mathrm{s}$. At earlier delay times, namely before $0.2 \mu \mathrm{s}$, the atomic lines were hidden under the well known con tinuum signal due to the bremsstrahlung and to recombination effects. For the longest delay times of this study and to improve the signal to noise ratio, the temporal gate width of the ICCD was increased in order to allow the detection of the low intensity UBS signal. As a conse quence, the measured signal was divided by the temporal gate width, in order to obtain comparable intensities for different delay times. Delays used in this paper correspond to the center of the temporal gate. Each spectrum resulted from the accumulation of 25 measurements at differ ent locations onto the sample surface. For each measurement, 50 laser
Table 1

Wavelengths $(\lambda)$, degeneracies $(g)$, Einstein coefficients $(A)$ and upper energy level values $\left(E_{\mathrm{k}}\right)$.

\begin{tabular}{llll}
\hline$\lambda(\mathrm{nm})$ & $g$ & $A\left(\mathrm{~s}^{1}\right)$ & $E_{\mathrm{k}}\left(\mathrm{cm}^{1}\right)$ \\
\hline 305.7144 & 6 & $7.50 \mathrm{E}+07$ & $61,843.54$ \\
305.0072 & 6 & $3.21 \mathrm{E}+07$ & $61,843.54$ \\
305.4679 & 4 & $4.49 \mathrm{E}+07$ & $61,747.56$ \\
306.6144 & 4 & $4.77 \mathrm{E}+07$ & $61,747.56$ \\
305.9030 & 4 & $1.41 \mathrm{E}+07$ & $61,747.56$ \\
305.9924 & 2 & $1.82 \mathrm{E}+07$ & $61,691.46$ \\
306.4290 & 2 & $8.91 \mathrm{E}+07$ & $61,691.46$ \\
\hline
\end{tabular}

shots were applied to obtain the resulting spectrum. In addition, two pre pulses were used in order to remove the oxide layer $\left(\mathrm{Al}_{2} \mathrm{O}_{3}\right)$ that was naturally formed at the sample surface.

\section{Results and discussions}

At first, Al I lines were examined at two different delay times and two different ambient gases. Fig. 2a displays the comparison between the LIBS spectra of the ultra pure aluminum sample under air (plain) and nitrogen (dashed) at a delay time of $0.8 \mu$ s. The two spectra reveal no significant differences. On the other hand, at a delay time of $4.5 \mu \mathrm{s}$, Fig. $2 \mathrm{~b}$ reveals a peculiar and significant difference between the recorded spectra since under nitrogen atmosphere, two Al I lines ( $305.007 \mathrm{~nm}$ and $305.714 \mathrm{~nm}$ ) were still visible while those under air atmosphere had vanished. These persistent $\mathrm{Al}$ I lines were related to two transitions with the same upper energy level $E_{\mathrm{k}}=61844 \mathrm{~cm}^{-1}$.

\subsection{Temporal evolution under nitrogen atmosphere}

Fig. 3 shows the temporal evolution of four Al I lines selected in the spectral range displayed in Fig. 2, in the case of plasma expansion in nitrogen atmosphere. The red curves are related to two transitions with the same upper energy level $E_{\mathrm{k}}=61844 \mathrm{~cm}^{-1}$, the blue ones to $E_{\mathrm{k}}=61748 \mathrm{~cm}^{-1}$ and the orange ones to $E_{\mathrm{k}}=61691 \mathrm{~cm}^{-1}$. In order to compare the temporal evolutions of these Al I transitions, all the inten sities were normalized to 1 at the delay time of $0.2 \mu \mathrm{s}$. The error bars

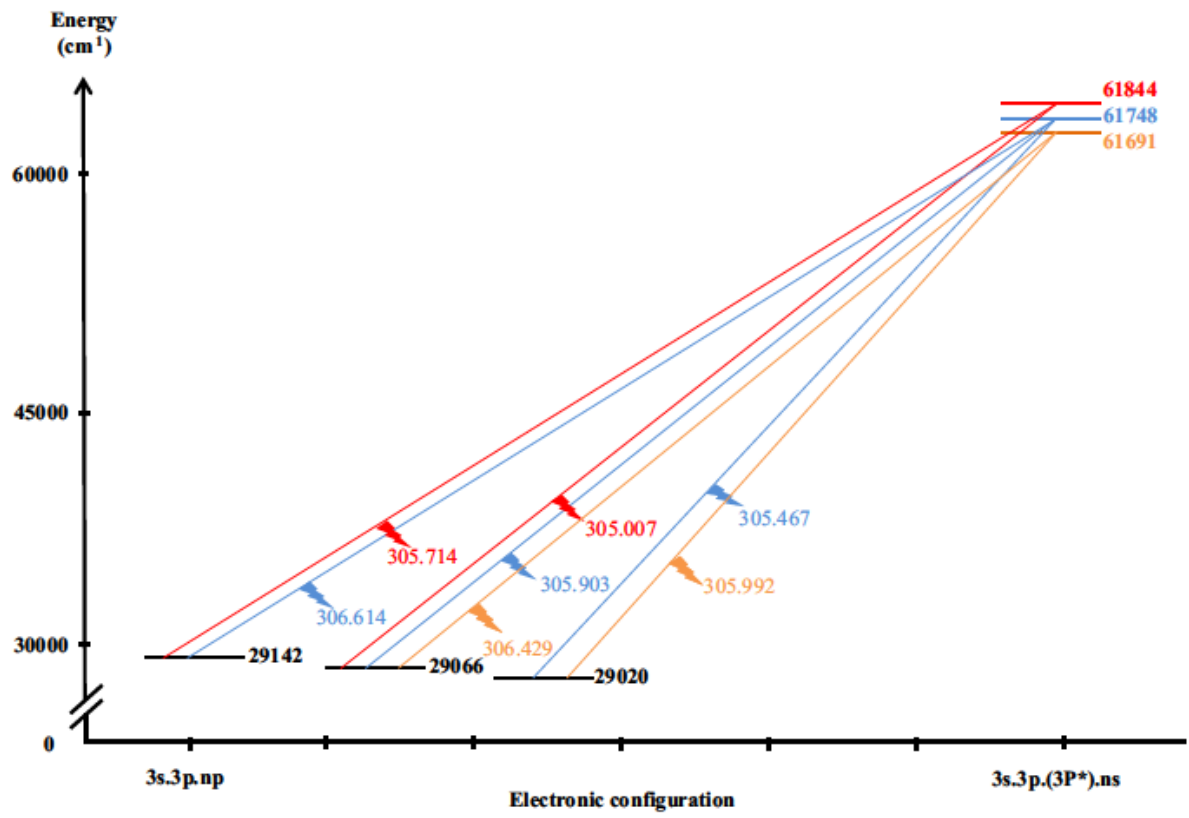

Fig. 1. Part of the Grotrian diagram of aluminum related to the observed spectral lines. 

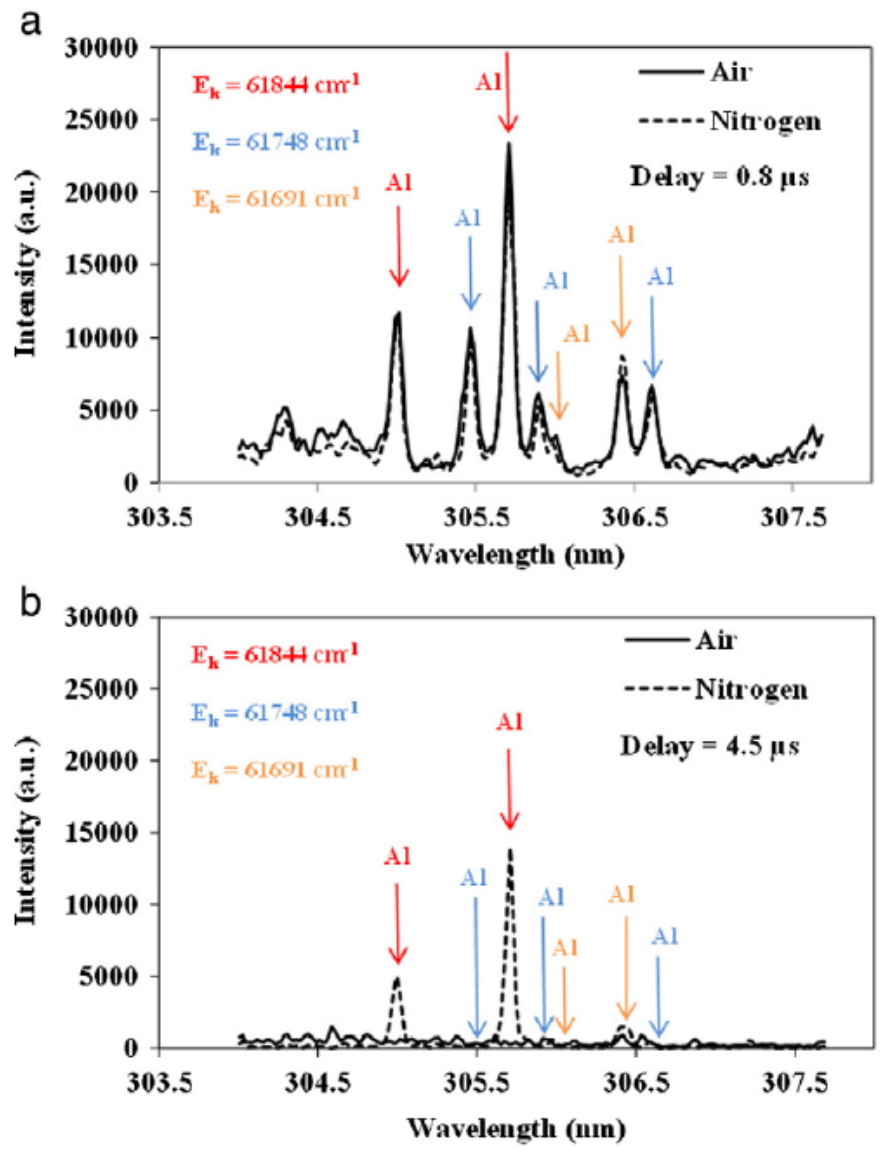

Fig. 2. UBS spectra of aluminum under nitrogen (dashed) and air (plain) atmospheres, for delay times of $0.8 \mu \mathrm{s}$ (a) and $4.5 \mu \mathrm{s}$ (b) after the laser pulse. All the detected lines were assigned to Al I.

represented the value $3 \sigma /(25)^{1 / 2}$ where $\sigma$ was the relative standard deviation calculated after a series of 25 measurements.

In Fig. 3, one can verify that there is no significant difference between the two red curves corresponding to transitions sharing the same upper energy level $E_{\mathrm{k}}=61844 \mathrm{~cm}^{-1}$. Moreover, the blue and the orange curves corresponding to transitions sharing the same upper energy level $E_{\mathrm{k}}=61748 \mathrm{~cm}^{-1}$ and $E_{\mathrm{k}}=61691 \mathrm{~cm}^{-1}$, respectively, are also overlapped. These results are not surprising since the intensity of an emission line is proportional to the population of the upper energy level. Consequently, transitions related to the same upper energy level are expected to follow the same temporal evolution. Nevertheless,

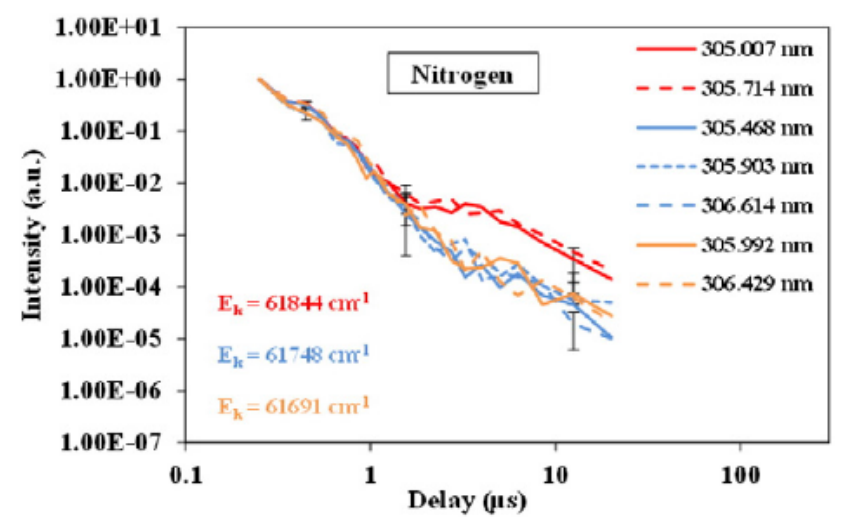

Fig. 3. Temporal evolution of the emission lines of aluminum under nitrogen atmosphere at ambient pressure.
Fig. 3 clearly demonstrates the existence of two regimes; the first one for delay times shorter than $1.5 \mu$ s where the red, blue and orange curves perfectly overlap, and the second one, longer than $1.5 \mu \mathrm{s}$, where the red curves are clearly separated by typically an order of mag nitude from the blue and the orange ones. In order to better understand Fig. 3, the difference between the three energy levels, namely $61844 \mathrm{~cm}^{-1}, 61748 \mathrm{~cm}^{-1}$ and $61691 \mathrm{~cm}^{-1}$ should be analyzed. Under local thermodynamic equilibrium (LTE) conditions, the populations of the energy levels are given by the Boltzmann distribution law [4]. Consequently, the intensities of these energy levels should similarly decrease as a function of temperature during the plasma cooling. More over, the three energy levels being very close to each other with a differ ence of only $153 \mathrm{~cm}^{-1}$, their populations should only differ by less than $2.2 \%$ at $10000 \mathrm{~K}$ as long as the LTE conditions are fulfilled. Thus, the data shown in Fig. 3 clearly reveal a strong deviation from LTE after $1.5 \mu \mathrm{s}$. This unexpected behavior could be explained by a coupling interaction between aluminum and nitrogen. More precisely, this result could be due to the existence of specific interactions with nitrogen involving se lectively the $61844 \mathrm{~cm}^{-1}$ upper energy level of aluminum which un dergoes collisional energy transfer from molecular nitrogen. This effect was not observed for the other detected Al I lines in the LIBS spectrum. On the other hand, this peculiar result can be related to the experimen tal observation by Clay and Niemczyk [32] where the energy levels of iron ( $\mathrm{Fe}$ ) could be excited by the presence of nitrogen ambient gas $\left(\mathrm{N}_{2}\right)$. We note here that, after $1.5 \mu \mathrm{s}$, the emission related to the upper level of aluminum at $61844 \mathrm{~cm}^{-1}$ was maintained to a value ten times higher than that originating from the upper levels at $61748 \mathrm{~cm}^{-1}$ and $E_{\mathrm{k}}=61691 \mathrm{~cm}^{-1}$. In addition, a molecular band of AlN was observed in the LIBS spectrum. Fig. 4 shows the temporal evolution of the AlN sig nal at $507.680 \mathrm{~nm}$ observed in the presence of nitrogen as background gas (triangle labels). The signal related to AlN appeared around $1.5 \mu \mathrm{s}$ and this value of delay time corresponds exactly to the separation of the red and blue/orange curves observed in Fig. 3. Note that we subtract the continuum background but a part of the continuum remains, mainly at short delay times $(<1 \mu \mathrm{s})$. Consequently, in addition to the selective energy transfer effect already mentioned, on should conclude that molecules of AlN are also created, typically after $1.5 \mu \mathrm{s}$. This delay time might be interpreted as the time necessary for nitrogen to be incorpo rated into the aluminum plasma.

It should be noticed that the creation of AlN molecules should affect the total number of remaining $\mathrm{Al}$ atoms. Thus, despite the temporal coincidence at $1.5 \mu \mathrm{s}$, the creation of AlN could not directly explain the different behavior of the three curves reported in Fig. 3 .

In order to gain a deeper insight in the persistence of the two Al I lines originating from the level $61844 \mathrm{~cm}^{-1}$ under nitrogen atmosphere, we compared in the following their temporal evolution between nitro gen and air background gases.

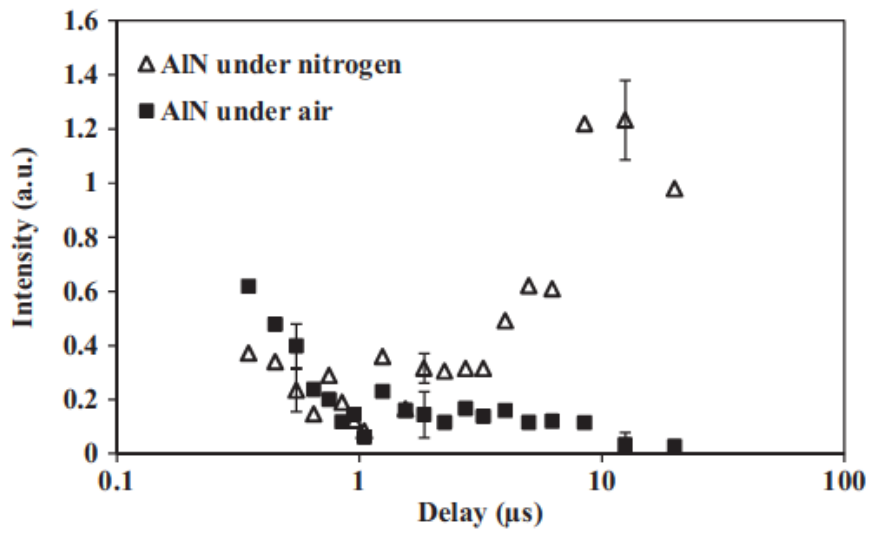

Fig. 4. Comparison between the temporal evolution of the AIN molecular band at $507,680 \mathrm{~nm}$ under nitrogen (triangle labels) and air (square labels) atmospheres. 
3.2. Comparison of the temporal evolution between nitrogen and air atmospheres

In the second part of this study, we substituted nitrogen by air and compared the temporal evolutions of the $\mathrm{AlI}$ lines for the same experi mental conditions. Fig. 5 shows a comparison of the temporal evolution of three Al I lines coming from different energy levels, namely $61,844 \mathrm{~cm}^{-1}, 61,748 \mathrm{~cm}^{-1}$ and $61,691 \mathrm{~cm}^{-1}$ under the two different atmo spheres, air and nitrogen. Considering that $M_{\text {nitrogen }}=28.02 \mathrm{~g} \mathrm{~mol}^{-1}$ and $\mathrm{M}_{\mathrm{air}}=28.97 \mathrm{~g} \mathrm{~mol}^{-1}$ are very close, the plasma expansion as well as the temperature decrease due to adiabatic expansion was considered to be very similar in both cases. Among the six curves displayed in Fig. 5, only the one related to the level of aluminum at $61,844 \mathrm{~cm}^{-1}$, for plasma expanding in nitrogen, presents a temporal evolution different from the three other ones. It should be stressed that, despite the concen tration of $80 \%$ of nitrogen in air, the temporal evolution of the spectral line related to this upper energy level of aluminum at $61,844 \mathrm{~cm}^{-1}$ was found to be very different in the two gases. In ambient air, the behavior of this level was the same as that of the $61,748 \mathrm{~cm}^{-1}$ and the $61,691 \mathrm{~cm}^{-1}$ energy levels. In other words, the collisional energy transfer that was observed for this energy level in nitrogen was not detected in air, indicating that the presence of $20 \%$ of oxygen eliminates this effect.

Moreover, it should be noticed that, even if air contains $80 \%$ of nitro gen, there was an extinction of the AlN emission band at $507.680 \mathrm{~nm}$ in the case of plasma expansion in air (Fig. 4). This observation was not surprising since the equilibrium constants for the reaction of formation of AlO and AIN, and denoted $\mathrm{K}_{\mathrm{AIO}}$ and $\mathrm{K}_{\mathrm{AIN}}$ respectively, always showed very different values, whatever the plasma temperature, as reported in Table 2. These values were calculated at various temperatures using the NIST JANAF Thermochemical Tables [33]. As a consequence, for plasma expanding in air, the presence of $20 \%$ oxygen is sufficient to completely suppress the detection of the AlN emission band and thus probably the formation of AlN molecules.

Furthermore, Fig. 6 shows the temporal evolution of the AlO molec ular band around $484.210 \mathrm{~nm}$ under air atmosphere. One can observe that the signal starts around $1.2 \mu$ s, i.e. at a delay time close to that obtained for the signal of AlN. As in the case of nitrogen, this could be interpreted as the typical time required for oxygen to be incorporated into the plasma. Here again note that we subtract the continuum back ground but a part of the continuum remains, mainly at short delay times $(<1 \mu s)$.

Finally, based on the comparison between air and nitrogen, we observed that the spectral lines related to the upper energy level at $61844 \mathrm{~cm}^{-1}$ revealed an unexpected temporal evolution, but only in the case of nitrogen atmosphere. Among the three energy levels that were studied, this level was the only one revealing an unexpected

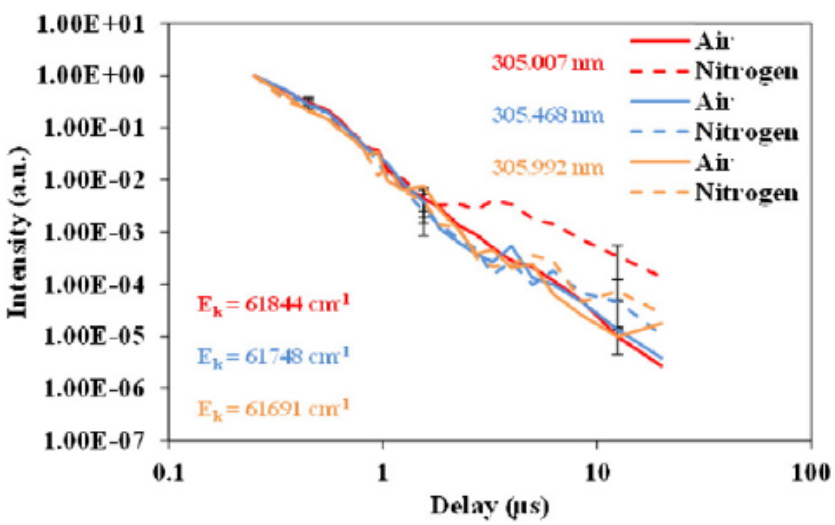

Fig. 5. Temporal evolution of different Al I lines under two different atmospheres (nitrogen and air). Plain lines: air; dashed lines: nitrogen. Red: upper level at $61844 \mathrm{~cm}^{1}$; blue: upper level at $61748 \mathrm{~cm}^{1}$; orange: upper level at $61,691 \mathrm{~cm}^{1}$.
Table 2

Equilibrium constants of $\mathrm{AlO}$ and AIN molecules for different plasma temperatures.

\begin{tabular}{lllllllll}
\hline $\mathrm{T}(\mathrm{K})$ & 3000 & & 4000 & 5000 & \multicolumn{3}{c}{6000} & \\
\hline $\mathrm{K}_{\text {AlO }}$ & 85.58 & & 6.7 & & 1.52 & & 0.57 & \\
$\mathrm{~K}_{\text {AIN }}$ & $8.18 \mathrm{E}$ & 06 & $5.6 \mathrm{E}$ & 05 & $1.77 \mathrm{E}$ & 04 & $3.8 \mathrm{E}$ & 04 \\
\hline
\end{tabular}

behavior, which was interpreted to be related to a collisional energy transfer effect between aluminum and nitrogen. Moreover, the amount of $20 \%$ oxygen contained in the air totally annihilated both the collisional energy transfer effect observed on the energy level of Al I at $61844 \mathrm{~cm}^{-1}$ and the formation of AlN molecules.

\section{Conclusion}

In this work, collisional energy transfer and molecular recombina tion effects between aluminum and nitrogen were observed in the case of aluminum plasma expanding in pure nitrogen. In addition, the presence of oxygen in air totally suppressed both the collisional energy transfer and the formation of AlN while inducing the formation of AlO. These effects generated a deviation from the local thermodynamic equilibrium after $1.5 \mu$ for the experimental conditions reported here. As a consequence, the energy levels that are unexpectedly affected during UBS analysis could induce a bias for both the calculation of the plasma temperature via the so called Boltzmann plot and also for build ing a calibration curve in order to retrieve the concentration from the LIBS signal. Thus the performances of both quantitative approaches, namely with or without calibration, might be impacted.

Finally, the results presented in this paper should alert the LIBS analyst to carefully select spectral lines for which no abnormal effect was ob served. Short delay time could be a solution to do "'not let the time for mixing between plasma and ambient gas and so to prevent unwanted collisional effect and molecular recombination. The peculiar collisional ef fect was selective for the only energy level $61,844 \mathrm{~cm}^{-1}$. This selectivity remains unexplainable until now. Moreover, plasma expansion in inert gases might be a solution in order to suppress both collisional energy transfer effects and molecular recombination with atoms of the back ground gas. This point might be specifically addressed in the future in order to evaluate the best experimental conditions for accurate quantita tive LIBS. This work highlights the possible influence of collisional and chemical effects inside the plasma that can play a role on UBS signals.

\section{Acknowledgments}

This work has been supported by the project Analytical Sciences (SCIAN) of the Nuclear Energy Direction (DEN) of the CEA.

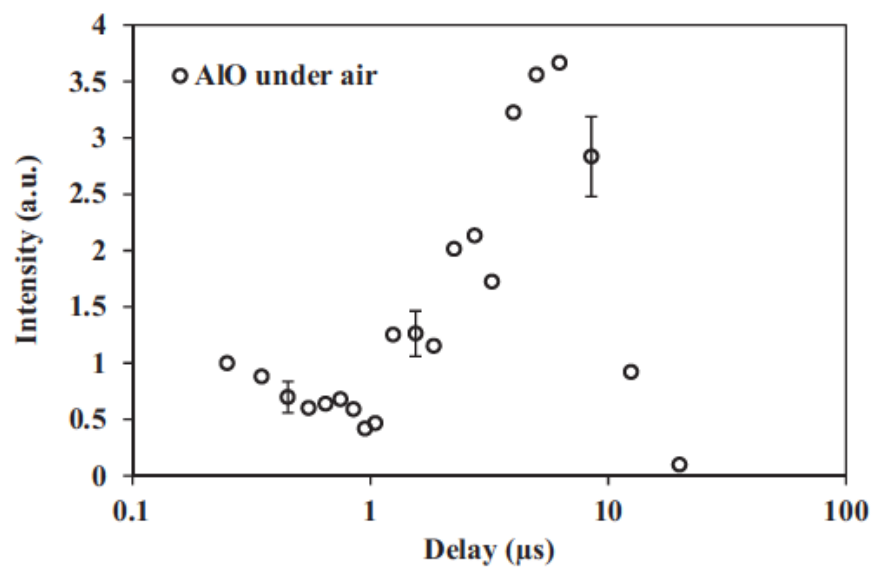

Fig. 6. Temporal evolution of the AlO molecular band at $484.210 \mathrm{~nm}$ under air atmosphere. 


\section{References}

[1] D.W. Hahn, N. Omenetto, Laser-induced breakdown spectroscopy (LIBS), part I: review of basic diagnostics and plasma-particle interactions: still-challenging issues within the analytical plasma community, Appl. Spectrosc. 64 (2010) 335-366.

[2] D.W. Hahn, N. Omenetto, Laser-induced breakdown spectroscopy (LIBS), part II: review of instrumental and methodological approaches to material analysis and applications to different fields, Appl. Spectrosc. 66 (2012) 347-419.

[3] D.A. Cremers, L.J. Radziemski, Hand Book of Laser-Induced Breakdown Spectroscopy, John Wiley and Sons Ltd., England, 2006.

[4] H.R. Griem, Principles of Plasma Spectroscopy, Cambridge University Press, Cambridge, 1997.

[5] S. Maurice, et al., The ChemCam Instrument Suite on the Mars Science Laboratory (MSL) Rover: Science Objectives and Mast Unit Description, Space Sci. Rev. 170 (2012) 95-166.

[6] R. Wiens, et al., The ChemCam Instrument Suite on the Mars Science Laboratory (MSL) Rover: Body Unit and Combined System Tests, Space Sci. Rev. 170 (2012) 167-227.

[7] C.M. Davies, H.H. Telle, A.W. Williams, Remote in situ analytical spectroscopy and its applications in the nuclear industry, Fresenius J. Anal. Chem. 355 (1996) 895-899.

[8] P. Fichet, P. Mauchien, C. Moulin, Determination of impurities in uranium and plutonium dioxides by laser-induced breakdown spectroscopy, Appl. Spectrosc. 53 (1999) 1111-1117.

[9] A. Brysbaert, K. Melessanaki, D. Anglos, Pigment analysis in Bronze Age Aegean and Eastern Mediterranean painted plaster by laser-induced breakdown spectroscopy (LIBS), J. Archaeol. Sci. 33 (2006) 1095-1104.

[10] D. Anglos, S. Couris, C. Fotakis, Laser diagnostics of painted artworks: laser-induced breakdown spectroscopy in pigment identification, Appl. Spectrosc. 51 (1997) 1025-1030.

[11] G. Gallou, J.B. Sirven, C. Dutouquet, O.L. Bihan, E. Frejafon, Aerosols analysis by LIBS for monitoring of air pollution by industrial sources, Aerosol Sci. Tech. 45 (2011) 918-926.

[12] U. Panne, R.E. Neuhauser, M. Theisen, H. Fink, R. Niessner, Analysis of heavy metal aerosols on filters by laser-induced plasma spectroscopy, Spectrochim. Acta Part B 56 (2001) 839-850.

[13] R. Sattmann, I. Monch, H. Krause, R. Noll, S. Couris, A. Hatziapostolou, A. Mavromanolakis, C. Fotakis, E. Larrauri, R. Miguel, Laser-induced breakdown spectroscopy for polymer identification, Appl. Spectrosc. 52 (1998) 456-461.

[14] J. Jasik, J. Heitz, J.D. Pedarnig, P. Veis, Vacuum ultraviolet laser-induced breakdown spectroscopy analysis of polymers, Spectrochim. Acta Part B 64 (2009) 1128-1134.

[15] R. Noll, H. Bette, A. Brysch, M. Kraushaar, I. Monch, L. Peter, V. Sturm, Laser-induced breakdown spectrometry-applications for production control and quality assurance in the steel industry, Spectrochim. Acta Part B 56 (2001) 637-649.

[16] J. Gruber, J. Heitz, N. Arnold, D. Bäuerle, N. Ramaseder, W. Meyer, J. Hochörtler, F. Koch, In situ analysis of metal melts in metallurgic vacuum devices by laserinduced breakdown spectroscopy, Appl. Spectrosc. 58 (2004) 457-462.
[17] R.S. Harmon, F.C. DeLucia, C.E. McManus, N.J. McMillan, T.F. Jenkins, M.E. Walsh, A Miziolek, Laser-induced breakdown spectroscopy-an emerging chemical sensor technology for real-time field-portable, geochemical, mineralogical, and environmental applications, Appl. Geochem. 21 (2006) 730-747.

[18] R. Bruder, D. L'Hermite, A. Semerok, L. Salmon, V. Detalle, Near-crater discoloration of white lead in wall paintings during laser induced breakdown spectroscopy analysis, Spectrochim. Acta Part B 62 (2007) 1590-1596.

[19] R. Bruder, V. Detalle, C. Coupry, An example of the complementarity of laser-induced breakdown spectroscopy and Raman microscopy for wall painting pigments analysis, J. Raman Spectrosc. 38 (2007) 909.

[20] L. St-Onge, E. Kwong, M. Sabsabi, E.B. Vadas, Quantitative analysis of pharmaceutica products by laser-induced breakdown spectroscopy, Spectrochim. Acta Part B 57 (2002) 1131-1140.

[21] M. Baudelet, L. Guyon, J. Yu, J.-P. Wolf, T. Amodeo, E. Frejafon, P. Laloi, Spectra signature of native $\mathrm{CN}$ bonds for bacterium detection and identification using femtosecond laser-induced breakdown spectroscopy, Appl. Phys. Lett. 88 (2006) 063901.

[22] D.A. Cremers, J.E. Barefield, A.C. Koskelo, Remote elemental analysis by laserinduced breakdown spectroscopy using a fiber-optic cable, Appl. Spectrosc. 49 (1995) 857-860.

[23] N.B. Zorov, A.A. Gorbatenko, T.A. Labutin, A.M. Popov, A review of normalization techniques in analytical atomic spectrometry with laser sampling: from single to multivariate correction, Spectrochim. Acta Part B 65 (2010) 642-657.

[24] P.J. Dagdigian, H.W. Cruse, R.N. Zare, Laser fluorescence study of AlO formed in the reaction $\mathrm{Al}+\mathrm{O}_{2}$ : product state distribution, dissociation energy, and radiative lifetime, J. Chem. Phys. 62 (1975) 1824-1833.

[25] K. Honma, Reaction dynamics of $\mathrm{Al}+\mathrm{O} 2 \rightarrow \mathrm{AlO}+\mathrm{O}$ studied by the crossed-beam laser-induced fluorescence technique, J. Chem. Phys. 119 (2003) 3641-3649.

[26] A. Misra, R.K. Thareja, Laser ablation deposition of metal oxides/nitrides films at room temperature, J. Appl. Phys. 86 (1999) 3438-3441.

[27] A.K. Sharma, R.K. Thareja, Pulsed laser ablation of aluminum in the presence of nitrogen: formation of aluminum nitride, J. Appl. Phys. 88 (2000) 7334-7338.

[28] I.G. Dors, C. Parigger, J.W.L. Lewis, Spectroscopic temperature determination of aluminum monoxide in laser ablation with 266-nm radiation, Opt. Lett. 23 (1998) 1778.

[29] C.G. Parigger, Atomic and molecular emissions in laser-induced breakdown spectroscopy, Spectrochim. Acta Part B 79-80 (2013) 4-16.

[30] R. Bruder, Laser-induced breakdown spectroscopy studies and development for field analysis: example of application to artworks, Thèse de doctorat en Chimie analytique-Université Pierre et Marie Curie-Paris VI, 2008.

[31] R.L. Kurucz, Kurucz atomic spectral line database, http://www.pmp.uni-hannover. de/cgi-bin/ssi/test/kurucz/sekur.html.

[32] J.T. Clay, T.M. Niemczyk, Factors influencing iron excitation in nitrogen/rare gas microwave plasmas, Spectrochim. Acta Part B 47 (1992) 835.

[33] NIST-JANAF, Thermochemical Tables, http://kinetics.nist.gov/janaf/. 